\title{
Petroleum Product as Substrate for the Production of Biosurfactive Amphiphlies by Pseudomonas Aeruginosa
}

\author{
${ }^{* 1}$ M.B. Tijjani, ${ }^{1}$ M.S. Aliyu, ${ }^{1}$. Garba, ${ }^{1}$ H.I.D. Muhammad and ${ }^{1}$ I.A. Muhammad \\ 1Department of Microbiology, Ahmadu Bello University Zaria \\ [Corresponding Author: Email: mbtijjani@yahoo.com, bashtj@hotmail.com]
}

\section{ABSTRACT}

Biosurfactant production by Pseudomonas aeruginosa by utilizing diesel as the source of energy and carbon was studied in this research. Biosurfactant-producing strain of the organism was isolated from hydrocarbon-contaminated water and grown in a mineral medium supplemented with diesel. Production of biosurfactant was assayed by monitoring the increase in cell concentration, biosurfactant concentration, emulsification index and decrease in surface tension. Highest level of cell concentration and biosurfactant concentration $\left(3.3^{\wedge} 10^{8} \mathrm{CFU} / \mathrm{ml}\right.$ and $0.0108 \mathrm{mg} / \mathrm{ml}$ respectively) were obtained at $132 \mathrm{hrs}$. Emulsification index reached its maximum with $33.3 \%$ at $108 \mathrm{hrs}$. Surface tension reached its minimum at $120 \mathrm{hrs}$ with a value of $1.1^{\wedge} 10^{-6} \mathrm{~N} / \mathrm{m}$. The results showed that diesel can be utilized by $P$. aeruginosa to produce biosurfactant and early stationary phase isolates can be used to obtain higher yield. It also revealed the increasing potentiality of microorganisms in the aspect of oil spill cleanup and rapid reclamation of contaminated lands and water bodies.

Keywords: Biosurfactant, diesel, surface tension, emulsification index, cell biomass, Pseudomonas aeruginosa.

\section{INTRODUCTION}

Our daily routine basic activities are mostly dependent on the use of some kind of surfactants or emulsifiers including toothpaste, personal hygiene, cosmetic products, and other pharmaceutical by-products, most of which contain surfactants and emulsifier as one of their ingredients (Banat et al., 2014). Microbial production of surfactants increasingly gains attention due to the strong surface activity and specific characteristics of some of these biosurfactants (Willenbacher et al., 2015). Production of biosurfactants has increased in recent years due to their biodegradability, reduced toxicity and diverse application compared to synthetic surfactants (PaniaguaMichel et al., 2014). They have low toxicity and are biodegradable because they can reduce interfacial tension, surface tension (ST), and the critical micelle concentration (CMC) (Dadrasnia and Ismail, 2015). These metabolic bioactive products are applicable in a number of industries and processes, viz., food processing, pharmacology, and bioremediation of oil-polluted environments (Paniagua-Michel et al., 2014). They are capable of spontaneous assemblies at the air-water or water-oil interface and thereby reducing surface/interfacial tensions due to their hydrophilic and hydrophobic structural components (Liu et al., 2015). They can be used as beneficial food elements and detergents in many industrial regions such as: organic chemicals, pharmaceuticals and cosmetics, beverages and foods, metallurgy, mining, petroleum, petrochemicals, biological control and management and many others (El azzazy et al.,2015; Rahman and Randhawa 2015). It is well-established that along with environmental parameters such as $\mathrm{pH}$, temperature, aeration, agitation, $\mathrm{CO}_{2}$ level etc.; $\mathrm{BS}$ production is also dependent on the substrate composition and concentration in the media (Banat et al., 2014). It is important to note that although a number of developments have taken place in the field of BS industries; large scale production remains economically challenging for many types of these products (Liu et al., 2015). Oil contamination with petroleum hydrocarbons has caused critical 
environmental and health defects and increasing attention has been paid for developing and implementing innovative technology for cleaning up this contamination. Bioremediation methods are currently receiving favourable publicity as promising environmentally friendly treatment technologies for the remediation of hydrocarbons

\section{MATERIALS AND METHODS Isolation, Characterization and Screening for Biosurfactant Production}

Water samples were collected in sterile Bijou bottles from car-wash run-off water contaminated with oil. Cetrimide agar was prepared, allowed to $\mathrm{cool}$ and dispensed in $20 \mathrm{ml}$ into five agar plates. Four plates were inoculated with the water sample and one was left uninoculated as control. The plates were incubated at $37^{\circ} \mathrm{C}$ for $24 \mathrm{hrs}$ (Murray et. al., 1999). Colonies obtained were subcultured on agar slant and stored in a refrigerator. Overnight culture of the isolates were subjected to the following biochemical tests: catalase, oxidase, motility. Other physiological and morphological characterizations carried out were: pigmentation on cetrimide agar and growth at $4{ }^{\circ} \mathrm{C}$.

A loopful of 24hrs broth culture of the isolate was streaked on fresh Cetrimide agar and incubated at $370^{\circ} \mathrm{C}$ for $48 \mathrm{~h}$ (Vanessa et al., 2009). Colonies with dark blue coloration against the pale blue background (colour of the methylene bluesupplemented medium) indicates biosurfactant production which is due to the formation of surfactant-methylene blue complex which gives the dark blue coloration (Van Hamme et al., 2003).

\section{The Substrate for Biosurfactant Production}

The diesel used in the research was obtained from Filling Station and was used throughout the study. Mineral medium was prepared by dissolving $0.4 \mathrm{~g}$ potassium phosphate, $0.4 \mathrm{~g}$ sodium phosphate, $0.2 \mathrm{~g}$ iron (II) sulphate, $2 \mathrm{~g}$ ammonium chloride, $0.4 \mathrm{~g}$ calcium chloride and $0.2 \mathrm{~g}$ magnesium sulphate in $250 \mathrm{ml}$ Erlenmeyer flask containing $200 \mathrm{ml}$ of distilled water.
Triplicate of the medium were prepared, two were inoculated with the test organism and one was left uninoculated as the negative control. The preparations were sterilized and supplemented with $4 \mathrm{ml}$ of petroleum diesel each, i.e. $2 \%$ of the total preparation (Rahman et. al., 2002).

\section{Inoculation and Incubation}

One (1) $\mathrm{ml}$ of $24 \mathrm{~h}$ broth culture of the isolate was pipetted into each of the test media using a sterile pipette, ensuring that the pipette has penetrated the layer of the diesel supplement. The other was used as control. The density of the medium was determined by differential weighing method and calculated using the formula:

Density $(\delta)=$ mass/volume

The flasks were incubated at $25^{\circ} \mathrm{C}$ in a water bath shaker (SHA-C) for seven (7) days at 120rpm. Six (6) ml samples of the culture broth were collected at $12 \mathrm{hrs}$ intervals for the seven days period (Thavasi et. al., 2009).

For each sample, the surface tension, emulsification index, cell biomass and biosurfactant concentration were determined.

\section{Measurement of Surface Tension}

Four (4) $\mathrm{ml}$ of the broth was transferred into a test tube and a clean capillary tube was immersed in it. The diameter of the capillary tube was measured. The height of the liquid that freely ascended into the capillary column was measured in duplicate (i.e. two trials) using a travelling microscope (least count $0.01 \mathrm{~mm}$ ).

The surface tension was calculated from the relation:

$Y=\operatorname{rh} \delta g / 2$

Where:

$Y=$ surface tension $(\mathrm{N} / \mathrm{m})$

$r=$ capillary radius $(\mathrm{m})$

$\delta=\operatorname{density~}(\mathrm{g} / \mathrm{ml})$

$\mathrm{h}=$ height of the liquid in the column $(\mathrm{m})$

$g=\operatorname{gravity}\left(9.8 \mathrm{~m} / \mathrm{s}^{2}\right)$ (Munguia and Smith, 2001). 


\section{Measurement of Emulsification Index}

Four $\mathrm{ml}$ of the broth was transferred into a test tube and vortexed for 2 mins. The tube was kept at room temperature for $24 \mathrm{hrs}$, after which the height of the emulsion layer and the total height of the solution in the tube were measured and the emulsification index (EI) was calculated using the formula:

$\mathrm{E}_{24}=$ height of the emulsion layer/height of the total solution $\times 100$

Where

$E_{24}=$ emulsification index (El) after 24hrs at room temperature (Sabina et. al., 2010).

\section{Turbidimetric Measurement of Cell Concentration (Biomass)}

To measure the biomass of the inoculum at the intervals of $12 \mathrm{hrs}, 1 \mathrm{ml}$ of the broth was transferred into a clean $1 \mathrm{~cm}$ cuvette. The optical density was measured spectrophotometrically at $600 \mathrm{~nm}$. MacFarland Standard 0.5 (absorbance 0.153, equivalent cell concentration $1.5^{\wedge} 10^{8} \mathrm{CFU} / \mathrm{ml}$ ) was used as the standard. The values were recorded in $\mathrm{CFU} / \mathrm{ml}$. (Thavasi et. al., 2009). McFarland turbidity standard was prepared by dissolving $0.5 \mathrm{~g}$ of barium chloride $\left(\mathrm{BaCl}_{2}\right)$ in $50 \mathrm{ml}$ of distilled water. To $99 \mathrm{ml}$ of sulphuric acid solution, $0.6 \mathrm{ml}$ of the barium chloride solution was added. The tube was carefully stoppered and stored in a dark drawer (Cheesbrough, 2000).

Biomass (in $\mathrm{CFU} / \mathrm{ml}$ ) was calculated using the relation:

$A_{M C} / B E_{M C}=A_{C B} / B E_{C B}$

Where

$A_{M C}=$ Absorbance of McFarland 0.5 standard solution at $500 \mathrm{~nm}$

$\mathrm{BE}_{\mathrm{MC}}=$ Biomass Equivalence of McFarland 0.5 standard solution

$A_{C B}=$ Absorbance of culture broth at $500 \mathrm{~nm}$

$\mathrm{BE}_{\mathrm{CB}}=$ Biomass Equivalence of broth culture.

\section{Spectrophotometric Measurement of} Biosurfactant Concentration

Methylene blue $(0.015 \mathrm{mg} / \mathrm{ml})$ was used as the standard and its optical density was measured at $500 \mathrm{~nm}$. Two (2) $\mathrm{ml}$ of the cell suspension was pipetted into a test tube and $2 \mathrm{ml}$ of chloroform was added, followed by a drop of $0.015 \mu \mathrm{g} / \mathrm{ml}$ methylene blue. The preparation was vortexed for 2 mins and the uppermost bluish layer (containing biosurfactant-methylene blue complex) was siphoned using Pasteur pipette into a clean dry $1 \mathrm{~cm}$ cuvette. The absorbance of the solution was measured at 500nm (Pinzon and Ju, 2009). The concentration was calculated from the formula:

$A_{m} / C_{m}=A_{b m} / C_{b m}$

Where:

$A_{m}=$ Absorbance of standard methylene blue solution at $500 \mathrm{~nm}$

$\mathrm{C}_{\mathrm{m}}=$ Concentration of standard methylene blue solution.

$A_{b m}=$ Absorbance of methylene bluebiosurfactant complex at $500 \mathrm{~nm}$

$\mathrm{C}_{b m}=$ Concentration of methylene bluebiosurfactant complex.

\section{RESULTS AND DISCUSSION}

From the results of biochemical characterization of the isolate (Table 1), inference was drawn as to the identity of the organism. Growth was observed on cetrimide agar after 24hrs of incubation but no growth was observed at $4^{\circ} \mathrm{C}$. Intense blue pigmentation of colonies formed by the isolates when subcultured on CTAB-MB agar was used as the criteria for isolation of biosurfactant-producing strains. The coloration was due to formation of methylene bluebiosurfactant complex (intense blue) and the complexation is thought to be due to the reaction of unsaturated methylene carbon the polar group of biosurfactant (Pinzon and Ju, 2009).

Biosurfactant concentration was measured indirectly by measuring the absorbance of biosurfactant-methylene blue complexation at $500 \mathrm{~nm}$ wavelength. The concentration of the complex was measured using $0.015 \mathrm{mg} / \mathrm{ml}$ methylene blue as the standard solution (optical density 0.848). Highest concentration $(0.0108 \mathrm{mg} / \mathrm{ml})$ was obtained on the $6^{\text {th }}$ day Table 2), after which the concentration began to decline. Sharp rise in the concentration was 
noticed from 120-132h indicating active biosurfactant synthesis.

Table 1: Biochemical characterization of the isolate.

\begin{tabular}{|c|c|c|}
\hline $\mathrm{S} / \mathrm{N}$ & Characteristic & Reaction \\
\hline 1 & $\begin{array}{l}\text { Growth on Cetrimide } \\
\text { agar with pigmentation }\end{array}$ & Positive \\
\hline 2 & Pigment on agar plate & Bright green \\
\hline 3 & Microscopy & $\begin{array}{l}\text { Gram negative } \\
\text { rods }\end{array}$ \\
\hline 4 & Motility & Positive \\
\hline 5 & Catalase & Positive \\
\hline 6 & Oxidase & Positive \\
\hline 7 & $\begin{array}{l}\text { Pigmentation in broth } \\
\text { culture }\end{array}$ & $\begin{array}{l}\text { Bright green at } \\
\text { the top layer } \\
\text { with dirty brown } \\
\text { sediment }\end{array}$ \\
\hline 8 & Growth at $4^{\circ} \mathrm{C}$ & Negative \\
\hline 9 & $\begin{array}{l}\text { Colony colour on } \\
\text { Cetrimide/methylene } \\
\text { blue agar (CTAB-MB) }\end{array}$ & $\begin{array}{l}\text { Intense blue } \\
\text { compared to the } \\
\text { agar } \\
\text { background }\end{array}$ \\
\hline & Inference & $\begin{array}{l}\text { Pseudomonas } \\
\text { aeruginosa }\end{array}$ \\
\hline
\end{tabular}

Cell concentration was measured indirectly by measuring the light absorbance of the broth culture at $650 \mathrm{~nm}$ using McFarland 0.5 (approximate biomass equivalence $=1.50^{\wedge} \mathrm{CFU} / \mathrm{ml}$, light absorbance at $650 \mathrm{~nm}=$ $0.153)$. Highest cell biomass $\left(3.33^{\wedge} 10^{8} \mathrm{CFU} / \mathrm{ml}\right)$ coincided with highest concentration of biosurfactant at $132 \mathrm{~h}$ as shown in Table 3. This indicates that biosurfactant production progresses proportionally with cell biomass
(Rahman et al., 2002) up to a stage where the production declines possibly due to accumulation of toxic wastes that characterizes most metabolic processes such as reactive free radicals. Attainment of critical micellar concentration (CMC), where increase in biosurfactant concentration has no effect of the surface tension of the medium may also reduce the availability of utilizable hydrocarbons for the organism. Deadend, impervious or toxic metabolites from the metabolism of more complex hydrocarbons like naphthalene, anthracene, alkylbenzene e.t.c may also be responsible for the decline in cell concentration of the organism which in turn affects the level of biosurfactant concentration Toxicity due to high concentration of surfactant or soluble hydrocarbon may also influence the rate and quantity of biosurfactant production by the organism. Some species of Pseudomonas were reported to preferentially metabolize the surfactant itself, thus reducing the quantity of the product. Interference with the membrane uptake process and reduced bioavailability of micellar hydrocarbons were also reported by Rouse et al. (1997) to affect the growth of the organism as well as level of biosurfactant production.

Table 2. Biosurfactant concentrations at the corresponding time intervals (in hrs).

\begin{tabular}{lll}
\hline Time & $\begin{array}{l}\text { Mean } \\
\text { Absorbance }\end{array}$ & $\begin{array}{l}\text { Biosurfactant } \\
\text { Concentration }(\mathrm{mg} / \mathrm{ml})\end{array}$ \\
\hline 12 & 0.044 & 0.00078 \\
24 & 0.188 & 0.0012 \\
36 & 0.241 & 0.0022 \\
48 & 0.262 & 0.0046 \\
60 & 0.293 & 0.0051 \\
72 & 0.362 & 0.0064 \\
84 & 0.308 & 0.0054 \\
96 & 0.385 & 0.0068 \\
108 & 0.473 & 0.0083 \\
120 & 0.590 & 0.0104 \\
132 & 0.669 & 0.0108 \\
144 & 0.628 & 0.0106 \\
156 & 0.578 & 0.0102 \\
\hline
\end{tabular}


Table 3. Cell concentrations (Biomass) at the corresponding time intervals (in hrs.)

\begin{tabular}{lll}
\hline Time & $\begin{array}{l}\text { Mean } \\
\text { Absorbance }\end{array}$ & $\begin{array}{l}\text { Cell } \\
\text { Concentration } \\
\text { (CFU/ml) }\end{array}$ \\
\hline 12 & 0.155 & $1.51^{\wedge} 10^{8}$ \\
24 & 0.153 & $1.50^{\wedge} 10^{8}$ \\
36 & 0.159 & $1.55^{\wedge} 10^{8}$ \\
48 & 0.193 & $1.89^{\wedge} 10^{8}$ \\
60 & 0.218 & $2.13^{\wedge} 10^{8}$ \\
72 & 0.233 & $2.28^{\wedge} 10^{8}$ \\
84 & 0.240 & $2.35^{\wedge} 10^{8}$ \\
96 & 0.294 & $2.88^{\wedge} 10^{8}$ \\
108 & 0.313 & $3.06^{\wedge} 10^{8}$ \\
120 & 0.313 & $3.06^{\wedge} 10^{8}$ \\
132 & 0.340 & $3.33^{\wedge} 10^{8}$ \\
144 & 0.272 & $2.66^{\wedge} 10^{8}$ \\
156 & 0.263 & $2.57^{\wedge} 10^{8}$ \\
\hline
\end{tabular}

No appreciable rise in cell biomas biomass was noticed from the $1^{\text {st }}$ to the $2^{\text {nd }}$ day and this may be due to the time lag for synthesis of inducible enzymes required for hydrocarbon utilization (Van Hamme et. al., 2003). Also from the results of biosurfactant concentration and cell biomass, it can be deduced that highest concentration of biosurfactant was obtained at the early stationery phase of growth of the organism (i.e. where exponential increase in cell concentration declines or ceases)

Measurement of surface tension was done by capillary method (capillary radius $=0.00045 \mathrm{~m}$, least count of the traveling microscope used $=$ $0.01 \mathrm{~mm})$. Lowest value of the interfacial tension $\left(1.1^{\wedge} 10^{-6} \mathrm{~N} / \mathrm{m}\right)$ was obtained at $120 \mathrm{~h}$ (Table 4). Subsequent irregularity in surface tension beyond $120 \mathrm{hrs}$ was possibly due to attainment of critical micellar concentration (CMC) of biosurfactant beyond which no further effect on surface tension was noticed (Mungiua and Smith, 2001 and Pornsunthorntawee et al., 2008).

The Emulsification indices $\left(E_{24}\right)$ at the respective time intervals were computed and expressed in percentage as shown in Table 5. The highest $\mathrm{E}_{24}$ $(33.3 \%)$ was obtained after $108 \mathrm{hrs}$ of incubation (12hrs earlier than the lowest value of surface tension) and the subsequent irregularity in the values may be due to the same reasons as in surface tension above (Rouse et. al., 1997).

It should however be noted that the fluctuations observed in the results obtained may be due to extrinsic factors such as temperature (surface tension measured this way was dependent on temperature, because density of the medium varied directly with the surface tension and density in turn varied with temperature), variation in particulate spectrophotometric absorbtivity, continuous agitation and aeration. Maintaining these parameters at constant rate may give a more linear result.

Table 4. Surface tension with respect to time intervals.

\begin{tabular}{lll}
\hline Time & Mean $\mathrm{h}(\mathrm{m})$ & $\begin{array}{l}\text { Surface } \\
\text { tension }(\mathrm{N} / \mathrm{m})\end{array}$ \\
\hline 12 & 0.00131 & $3.0^{\wedge} 10^{-6}$ \\
24 & 0.00133 & $3.1^{\wedge} 10^{-6}$ \\
36 & 0.00122 & $2.9^{\wedge} 10^{-6}$ \\
48 & 0.00120 & $2.8^{\wedge} 10^{-6}$ \\
60 & 0.00114 & $26^{\wedge} 10^{-6}$ \\
72 & 0.00098 & $2.3^{\wedge} 10^{-6}$ \\
84 & 0.00081 & $1.9^{\wedge} 10^{-6}$ \\
96 & 0.00077 & $1.8^{\wedge} 10^{-6}$ \\
108 & 0.00068 & $1.6^{\wedge} 10^{-6}$ \\
120 & 0.00050 & $1.1^{\wedge} 10^{-6}$ \\
132 & 0.00072 & $1.6^{\wedge} 10^{-6}$ \\
144 & 0.00094 & $2.2^{\wedge} 10^{-6}$ \\
156 & 0.00100 & $2.4^{\wedge} 10^{-6}$ \\
\hline
\end{tabular}


Table 5. Values of Emulsification indices at the respective time intervals

\begin{tabular}{ll}
\hline Time & $\begin{array}{l}\text { Mean Emulsification } \\
\text { Index (E24) }\end{array}$ \\
\hline 12 & 12.3 \\
24 & 12.9 \\
36 & 14.4 \\
48 & 15.7 \\
60 & 17.1 \\
72 & 21.5 \\
84 & 22.3 \\
96 & 26.9 \\
108 & 33.3 \\
120 & 29.9 \\
132 & 31.7 \\
144 & 31.5 \\
156 & 31.8 \\
\hline
\end{tabular}

\section{CONCLUSION}

Biosurfactive amphiphiles can be produced by strains of Pseudomonas aeruginosa utilizing diesel as the sole carbon source if provided with the necessary mineral nutrients required for optimum growth and metabolic processes. Also early stationery phase isolate of the organism can be used in order to obtain maximum yield.

\section{REFERENCES}

Banat, I.M., Satpute, S.K., Cameotra, S.S., Patil, R., and Nyayanit,N.V. (2014). Cost effective technologies and renewable substrates for biosurfactants' production, Frontiers in Microbiology, 5:697. Cheesbrough, M. (2000) District Laboratory Practice for Tropical Countries. Cambridge University Press. United Kingdom.

Dadrasnia, A. and Ismail, S. (2015). Biosurfactant production by Bacillus salmalaya for lubricating oil solubilization and biodegradation. International Journal of Environmental Research and Public Health, 12(8):9848-9863.
Elazzazy,A.M., Abdelmoneim, T.S. and Almaghrabi, O.A. (2015). Isolation and characterization of biosurfactant production under extreme environmental conditions by alkali-halo-thermophilic bacteria from Saudi Arabia. Saudi Journal of Biological Sciences, 22(4):466-475.

Liu, J.F., Mbadinga, S.M., Yang, S.Z., Gu, J.D. and $\mathrm{Mu}, \mathrm{B} . \mathrm{Z}$. (2015). Chemical structure, property and potential applications of biosurfactants produced by Bacillus subtilis in petroleum recovery and spill mitigation. International Journal of Molecular Science, 16(3):4814-4837.

Mungiua, T. and Smith, C.A. (2001) Surface Tension Determination through Capillary Rise and Laser Diffraction Patterns. Journal of Chemical Education 78:333343.

Murray, M.R., Bason E.J., Pfaller M.A., Tenover F.C. and Yolken, R.H. (1999) Manual of Clinical Microbiology (7th ed.). New York. American Society of Microbiology. Pp517-521.

Paniagua-Michel, J.J., Olmos-Soto, J., MoralesGuerrero, E.R. (2014). Algal and microbial exopolysaccharides: new insights as biosurfactants and bioemulsifiers, Advanced Food and Nutrition Research,73:221-57.

Pinzon, N.M. and Ju, L.K. (2009) Analysis of Biosurfactants by Methylene Blue Complexation. Applied Microbiology and Biotechnology, 82(5):975-981

Pornsunthorntawee, O., Wongpanit P., Chavadej S., Abe M. and Rujiravanit, R. (2008). Structural and physiochemical characterization of crude biosurfactant produced by Pseudomonas aeruginoa SP4 isolated from petroleumcontaminated soil. Bioresource Technology, 99:1589-1595.

Rahman, K.S.M, Thahira-Rahman, Maclean J., Marchant S. and Bent, R. I.M. (2002) Rhamnolipid Biosurfactant Production by 
Strains of Pseudomonas aeruginosa Using Low Cost Raw Material. Biotechnology Program. 18(6): 12771281.

Rahman, K.S.M., Banat I.M., Thahira J., Thayumanava T. and Lakshmanaperumalsamy, P. (2002). Bioremediation of gasoline contaminated soil by a bacterial consortium amended with poultry litter, coir pith, and rhamnolipid biosurfactant. Bioresource Technology, 81(1):25 - 32.

Rahman, P.K.S.M and Randhawa, K.K.S. (2015). Microbiotechnology based surfactants and their applications. Frontiers in Microbiology, 6:1344.

Rouse, J. D., Sabatini D. A., Suflita J. M. and Harwell, J. H. (1997). Influence of surfactants on microbial degradation of organic compounds. Critical Reviews in Microbiology, 24:325-370.

Sabina, V.R., Martha Cristina P.R., Maria De Lourdes B.C., Jose Viruciot.M., Blanca Estela R.C. and Gundalupe, V.N.M. (2010) Selection of Biosurfactant/Bioemulsifier-producing Bacteria from Hydrocarbon Contaminated Soil. Brazilian Journal of Microbiology. 41(3):668-675.

Thavasi, R., Subramanyam Nambaru M., Jayalakshmi S., Balasubramanian T. and Ibrahim, M.B. (2009). Biosurfactant production by Azotobacter chroococcum isolated from the marine environment. Marine Biotechnology. 11(5):551-556.

Van Hamme, J. D., Singh A. and Ward O. P. (2003) Recent advances in petroleum microbiology Microbiology and Molecular Biology Reviews, 67(4): 503-549

Vanessa, W., Christoph S., and Rudolf H. (2009) Concept of the isolation of biosurfactant producing microorganisms. Madame Curie Bioscience Database. NCBI Bookshelf.

Willenbacher J., Yeremchuk, W., Mohr, T., Syldatk, C. and Hausmann, R. (2015). Enhancement of surfactin yield by improving the medium composition and fermentation process, AMB Express, 5:57. 